\title{
Estudio ultraestructural de la fagocitosis de promastigotes y amastigotes de Leishmania mexicana por la línea de células dendríticas FSDC
}

\author{
Ladys Sarmiento', Martha Ayala ${ }^{2}$, Sandra Peña ${ }^{1}$, Gerzaín Rodríguez ${ }^{3,4}$, \\ Zelandia Fermín ${ }^{5}$, Felix J Tapia ${ }^{6}$ \\ ${ }^{1}$ Unidad de Microscopía y Análisis de Imágenes, Instituto Nacional de Salud, Bogotá, D.C., Colombia \\ ${ }^{2}$ Laboratorio de Parasitología, Instituto Nacional de Salud, Bogotá, D.C., Colombia \\ ${ }^{3}$ Laboratorio de Patología, Instituto Nacional de Salud, Bogotá, D.C., Colombia \\ ${ }^{4}$ Facultad de Medicina, Universidad de la Sabana, Bogotá, D.C., Colombia \\ ${ }^{5}$ Laboratorio de Inmunología Celular, Universidad Central de Venezuela, Caracas, Venezuela. \\ ${ }^{6}$ Laboratorio de Biología Molecular, Universidad Central de Venezuela, Caracas, Venezuela.
}

Introducción. Las células dendríticas están presentes en la mayoría de los tejidos, ellas capturan y presentan antígenos para activar a los linfocitos $\mathrm{T}$.

Objetivo. Se describe ultraestructuralmente la fagocitosis de Leishmania mexicana por la línea de células dendríticas FSDC, una línea de células de Langerhans obtenida de la epidermis fetal de ratón, e inmortalizada por la transducción retroviral del oncogen v-myc.

Materiales y métodos. Se obtuvieron amastigotes de la lesión de ratones Balb/c y promastigotes a partir del cultivo $\left(24^{\circ} \mathrm{C}\right)$ de la lesión. Las FSDC se cultivaron con los parásitos en una proporción de 5 parásitos por célula, en medio IMDM, durante 24 horas. Los cultivos infectados y los controles se procesaron para microscopía electrónica de transmisión. Se hicieron cortes semifinos contrastados con azul de toluidina para evaluar porcentaje de fagocitosis y finos, contrastados con acetato de uranilo y citrato de plomo.

Resultados. El 13,42\% de las FSDC fagocitaron promastigotes; de ellas el $8 \%$ contenían un parásito y el restante $5,2 \%$ fagocitó dos o más. El $20 \%$ de las FSDC fagocitaron amastigotes; $10 \%$ contenían un parásito y $10 \%$ dos o más. Ultraestructuralmente se observaron promastigotes en contacto con las células por el flagelo o por el polo posterior. Los fagosomas que contenían promastigotes eran organelos estrechos con uno ó dos parásitos. Los que contenían amastigotes eran de gran tamaño $(8 \mu \mathrm{m})$ con uno o varios parásitos, libres 0 adosados a la membrana del fagosoma por su polo posterior.

Conclusión. La infección de las FSDC se caracterizó por una baja tasa de células infectadas al ser expuestas a promastigotes o amastigotes. La vacuola parasitofora presentó características similares a las de los macrófagos. En su mayoría las FSDC presentaban 1 a 3 parásitos por célula. Las observaciones plantean la necesidad de estudiar la relación entre capacidad de fagocitosis y función.

Palabras clave: células de Langerhans, Leishmania, fagocitosis, microscopía electrónica.

Phagocytosis of promastigotes and amastigotes of Leishmania mexicana by the FSDC dendritic cell line: Ultrastructural study

Introduction. Dendritic cells, which capture and present antigen to activate unprimed T cell, are found in most tissues.

Objective. This work describes the ultrastructure of Leishmania mexicana phagocytosis by the fetal skin dendritic cell (FSDC) line, a Langerhans cell line isolated from mouse fetal epidermis immortalized by retroviral transduction of the $\mathrm{v}$-myc oncogene.

Materials and methods. Leishmania amastigotes were obtained from mouse (BALB/c) lesion and promastigotes from culture $\left(24^{\circ} \mathrm{C}\right)$ of the lesion. FSDC cells were cultured with parasites $(5$ parasites per cell) using IMDM medium, during 24 hours. Control and infected cultures were processed for transmission electron microscopy. Semi-thin sections counterstained with toluidine 
blue to evaluate phagocytosis and thin sections counterstained with uranyl acetate and lead citrate were made.

Results. $13.42 \%$ of the FSDC phagocytosed promastigotes; $8 \%$ contained a single parasite and $5.2 \%$ phagocytosed 2 or more. $20 \%$ of the FSDC phagocytosed amastigotes; $10 \%$ contained a single parasite and $10 \%$ phagocytosed 2 or more. Ultrastructurally, promastigotes in contact with FSDC by the flagellum or the posterior pole were observed. The parasitophorous vacuoles harbouring promastigotes were small organelles containing one or two parasites each. Parasitophorous vacuoles containing amastigotes were larger ( $8 \mu \mathrm{m}$ diameter) with one or several parasites free or attached to the vacuole at the posterior pole.

Conclusion. The low rate of infected FSDC cells was characteristic and the parasitophorous vacuole showed similar characteristics to those observed in macrophages. The parasite density in the infected cells was 1 to 3 parasites per cell. These observations highlight the need to study the relationship between phagocytic capacity and function.

Key words: Langerhans cells, Leishmania, phagocytosis, electron microscopy.

Las células dendríticas son elementos clave del sistema inmune, centinelas en la periferia que alertan a los linfocitos $T$ de antígenos invasores y dirigen el montaje de una respuesta eficiente (1). En la epidermis y otros epitelios estratificados, la célula de Langerhans es la representante por excelencia del sistema de células dendríticas (2). La leishmaniasis cutánea es producida por la inoculación intradérmica del parásito por el vector, lo que hace pensar que las células de Langerhans tienen una participación crítica no sólo durante el proceso inflamatorio sino en el inicio de una respuesta específica (3). La interacción de las células de Langerhans con parásitos de Leishmania sp. se demostró en 1990 cuando Moll et al., empleando estas células recién aisladas de la epidermis de ratones Balb/c, encontraron que $20 \%$ de ellas fagocitaban amastigotes de Leishmania major en 24 horas; sin embargo, no se produjo interacción con promastigotes, la forma inoculada por el vector en la piel (4).

Más tarde, Udey et al., empleando células expandidas de piel fetal de ratones C57BL6 (FSDDC), obtuvieron $36 \%$ de fagocitosis de amastigotes mientras que solamente el $7 \%$ fagocitaron promastigotes (5). Estos resultados con células dendríticas derivadas de la piel,

\section{Correspondencia}

Ladys Sarmiento, Grupo de Microscopía y Análisis de Imágenes, Instituto Nacional de Salud, Avenida Calle 26 № 51-60, Oficina 233, Bogotá, D.C., Colombia

Teléfono: (571) 2207700 , extensión 453

Isarmiento@ins.gov.co

Recibido: 08/06/05; aceptado: 12/12/05 contrastan con los más altos porcentajes de fagocitosis que se logran cuando se emplean células dendríticas de otro origen, como las diferenciadas de médula ósea, en las que se han encontrado porcentajes de fagocitosis de amastigotes y promastigotes de $40 \%$ y $54 \%$, respectivamente, y de $76 \%$ y $80 \%(6,7)$.

Al emplear células dendríticas generadas a partir de monocitos de sangre periférica, se han obtenido porcentajes de fagocitosis de amastigotes y promastigotes de $58 \%$ y $38 \%$, respectivamente, y en el caso de células dendríticas derivadas de bazo se encontró un porcentaje de fagocitosis de promastigotes del $33 \%(8,9)$. Las células dendríticas son una población celular muy heterogénea, por lo que las diferencias reportadas en la fagocitosis de las diferentes formas del parásito pueden ser producto de múltiples factores, entre ellos, su origen.

El objetivo de este trabajo fue estudiar la capacidad de la línea de células dendríticas FSDC para fagocitar parásitos de Leishmania mexicana y determinar las características ultraestructurales de la interacción con cada una de las formas del parásito. Esta determinación ultraestructural no se había realizado previamente en el modelo estudiado, en el que la microscopía electrónica se ha empleado sólo como evidencia para documentar la infección.

\section{Materiales y métodos}

\section{Parásitos}

Se empleó la cepa de L. mexicana 000/00/WRL11 CL802, donada al banco de criopreservación 
del Laboratorio de Parasitología del Instituto Nacional de Salud (INS) por Robert Tesh de Yale University. La identidad de la cepa se confirmó por isoenzimas y anticuerpos monoclonales.

Los amastigotes se extrajeron de la lesión desarrollada en la almohadilla plantar de ratones BALB/c inoculados 9 semanas antes con $1 \times 10^{6}$ promastigotes en $50 \mu \mathrm{l}$ de solución salina estéril. El tejido obtenido se maceró en un filtro metálico con el émbolo de una jeringa plástica, adicionando lentamente $10 \mathrm{ml}$ de medio de Schneider. Con el fin de liberar los amastigotes de los macrófagos, la mezcla se pasó a través de agujas calibre 21 y 26 , se centrifugó a $246 \mathrm{~g}$ por 5 minutos y el sobrenadante se colocó en hielo por 1 hora para retirar los residuos adheridos a los amastigotes. Luego de centrifugar a $1.120 \mathrm{~g}$ por 5 minutos, el sedimento de amastigotes se resuspendió en medio de Schneider y se pasó por aguja número 29 para facilitar el recuento de los parásitos individuales (10). Antes de ponerlos en contacto con las células, los parásitos se lavaron en solución salina al $0,85 \%$ y se transfirieron a medio Iscove Modified Dubelcco Medium (IMDM).

Los promastigotes obtenidos del cultivo de tejido de la lesión de los ratones infectados, se mantuvieron en medio Schneider a $24^{\circ} \mathrm{C}$ hasta incrementar la población y 10 días después del último pasaje se lavaron en solución salina al $0,85 \%$ y se transfirieron a medio IMDM para ser puestos inmediatamente en contacto con las células, de la misma manera en que se procedió con los amastigotes.

\section{Células}

La línea FSDC fue amablemente suministrada por Paola Ricciardi-Castagnoli del Departamento de Biotecnología y Biociencias de la Universidad de Milán-Bicocca en Italia. La línea fue derivada de células dendríticas de piel fetal de ratón; si bien la suspensión de células se obtuvo de la epidermis, el crecimiento de algunos fibroblastos en los primeros pasajes no excluye contaminación dérmica. La línea fue inmortalizada por la transducción retroviral del oncogen v-myc (11); tiene características de célula de Langerhans como son la expresión de ATPasa de membrana (11), la hidrólisis de ADP pero no de ATP (12), además de un fenotipo de célula dendrítica mieloide inmadura (13). El cultivo se realizó en medio IMDM con $5 \%$ de suero fetal bovino inactivado, $2 \mathrm{mM}$ de L-glutamina, $100 \mathrm{UI} / \mathrm{ml}$ de penicilina, $100 \mu \mathrm{g} / \mathrm{ml}$ de estreptomicina y $0,05 \mathrm{mM}$ de mercaptoetanol, a $37^{\circ} \mathrm{C}$ y $5 \%$ de $\mathrm{CO}_{2}$.

\section{Cultivos de FSDC con los parásitos}

Las FSDC con una viabilidad mayor al $98 \%$ se colocaron en medio IMDM fresco (con 5\% de suero fetal bovino inactivado, $2 \mathrm{mM}$ de L-glutamina, $100 \mathrm{Ul} / \mathrm{ml}$ de penicilina, $100 \mu \mathrm{g} / \mathrm{ml}$ de estreptomicina y $0,05 \mathrm{mM}$ de mercaptoetanol) y se incubaron durante 30 minutos, tiempo requerido para su adherencia, a $37^{\circ} \mathrm{C}$ y $5 \%$ de $\mathrm{CO}_{2}$. Luego, las monocapas de FSDC se pusieron en contacto con promastigotes o amastigotes, en una proporción de 5 parásitos por célula. Los cultivos se incubaron durante 24 horas a $37^{\circ} \mathrm{C}$, con $5 \%$ de $\mathrm{CO}_{2}$. Como control se emplearon FSDC cultivadas en medio IMDM en las mismas condiciones, pero sin la adición de parásitos.

\section{Microscopía electrónica}

Veinticuatro horas después de poner en contacto las células con los parásitos, los cultivos se fijaron en glutaraldehído al $3 \%$ en solución tampón de fosfato $0,01 \mathrm{M}, \mathrm{pH} 7,2$, durante 1 hora, a temperatura ambiente. Luego se posfijaron en tetraóxido de osmio al $1 \%$ durante 1 hora, a la misma temperatura. Se deshidrataron en etanol de grados ascendentes, se infiltraron e incluyeron en resina epón-araldita. Se hicieron cortes semifinos de $1 \mu \mathrm{m}$ de espesor y cortes finos de $60 \mathrm{~nm}$ que se tiñeron con acetato de uranilo y citrato de plomo (14). Las muestras se observaron en un microscopio electrónico de transmisión Zeiss EM 109.

\section{Recuentos}

Por medio de la observación con microscopía de luz de los cortes de $1 \mu \mathrm{m}$ teñidos con azul de toluidina, se efectuó el recuento para calcular el porcentaje total de células con parásitos fagocitados y el porcentaje de células que habían fagocitado 2 o más parásitos.

Se contaron 200 células en cada uno de los tres experimentos independientes realizados por duplicado. 


\section{Resultados}

Veinticuatro horas después de poner en contacto las FSDC con promastigotes de L. mexicana, un $13,42 \%$ de ellas habían fagocitado los promastigotes. Los cultivos de FSDC puestos en contacto con amastigotes produjeron un porcentaje de fagocitosis de $20 \%$. Por lo menos, el $50 \%$ de las FSDC fagocitaron un solo parásito independientemente de su forma (cuadro 1). No fue posible inferir diferencias en los dos grupos, dada la dispersión de los datos.

Ultraestructuralmente, en los cultivos control se observaron FSDC con abundantes dendritas, núcleo periférico y citoplasma con gran cantidad de retículo endoplásmico granuloso, algunas mitocondrias y pocas vacuolas (figura 1).

Los cultivos de FSDC puestos en contacto con promastigotes mostraron la unión inicial del parásito a las células tanto por el flagelo como por el polo posterior (figuras 2 y 3 ). Los promastigotes se localizaban en vacuolas que adoptaban su forma y que presentaban un espacio muy reducido entre el parásito y la vacuola, máximo de 100 a $200 \mathrm{~nm}$ (figura 4). El 8\% de las células presentaba vacuolas con un sólo parásito y el $3 \%$ contenían dos por vacuola como se muestra en la figura 3. Ocasionalmente se observaron parásitos en degradación dentro de la vacuola, como lo evidencia la pérdida de ribosomas que deja una apariencia de espacios vacíos en el citoplasma del parásito (figura 5). Algunas células, aunque no habían fagocitado, presentaron abundante número de vacuolas citoplasmáticas (figura 6).

Los cultivos puestos en contacto con amastigotes presentaron células con fagosomas más grandes que los observados cuando se emplearon promastigotes, que llegaban a tener de 5 a 8 um, aun cuando dentro de ellos se encontrara un solo parásito (figura 7). Los amastigotes se encontraron adosados a la vacuola por su polo posterior y libre (figuras 7 y 8 ). Se pudo observar desde un solo amastigote hasta diez dentro de un mismo fagosoma (figura 8).

\section{Discusión}

Las células dendríticas son una población muy heterogénea. Su susceptibilidad a infectarse con Leishmania sp. parece depender no sólo del tipo y procedencia de la célula dendrítica sino también de la especie y estadio de Leishmania $s p$. empleada (15). Cuando se emplean células dendríticas derivadas de la epidermis como las células de Langerhans, se obtienen menores porcentajes de fagocitosis que cuando se emplea cualquier otro tipo de célula dendrítica. La línea celular FSDC mostró un comportamiento similar al reportado con las FSDDC en cuanto al porcentaje de células capaces de fagocitar el parásito $(36 \%$ de amastigotes y $7 \%$ de promastigotes) (5), bajo, si se compara con los

Cuadro 1. Porcentaje de fagocitosis de promastigotes y amastigotes de L. mexicana por la línea de células FSDC. Los resultados se expresan como el porcentaje promedio obtenido del recuento de 200 células en tres experimentos independientes realizados por duplicado.

\begin{tabular}{|c|c|c|c|c|c|c|}
\hline $\begin{array}{l}\text { Leishmania } \\
\text { mexicana }\end{array}$ & & $\begin{array}{l}\% \text { total de FSDC } \\
\text { con parásitos } \\
\text { fagosomas }\end{array}$ & \multirow{2}{*}{$\begin{array}{c}\% \text { de FSDC } \\
\text { con un } \\
\text { parásito }\end{array}$} & \multirow{2}{*}{$\begin{array}{c}\begin{array}{c}\% \text { de FSDC } \\
\text { con dos } \\
\text { parásitos }\end{array} \\
4.83\end{array}$} & \multirow{2}{*}{$\begin{array}{c}\begin{array}{c}\% \text { de FSDC } \\
\text { con tres } \\
\text { parásitos }\end{array} \\
2,17\end{array}$} & \multirow{2}{*}{$\begin{array}{c}\% \text { de FSDC } \\
\text { más de tres } \\
\text { parásitos }\end{array}$} \\
\hline Amastigotes & Media & 20,17 & & & & \\
\hline & $\mathrm{DE}$ & 14,77 & 6,92 & 5,26 & 1,78 & 2,04 \\
\hline & Coeficiente de variación & 73,23 & 68,67 & 108,83 & 82,13 & 66,00 \\
\hline \multirow[t]{3}{*}{ Promastigotes } & Media & 13,42 & 8,17 & 3,33 & 0,83 & 1,08 \\
\hline & $\mathrm{DE}$ & 2,91 & 2,38 & 1,33 & 0,52 & 0,74 \\
\hline & Coeficiente de variación & 21,66 & 29,15 & 39,87 & 61,97 & 67,94 \\
\hline \multirow[t]{3}{*}{ Total } & Media & 16,79 & 9,13 & 4,08 & 1,50 & 2,08 \\
\hline & Des. estándar & 10,74 & 5,04 & 3,74 & 1,43 & 1,79 \\
\hline & Coeficiente de variación & 63,97 & 55,20 & 91.61 & 95,35 & 86.13 \\
\hline
\end{tabular}

DE: desviación estándar 


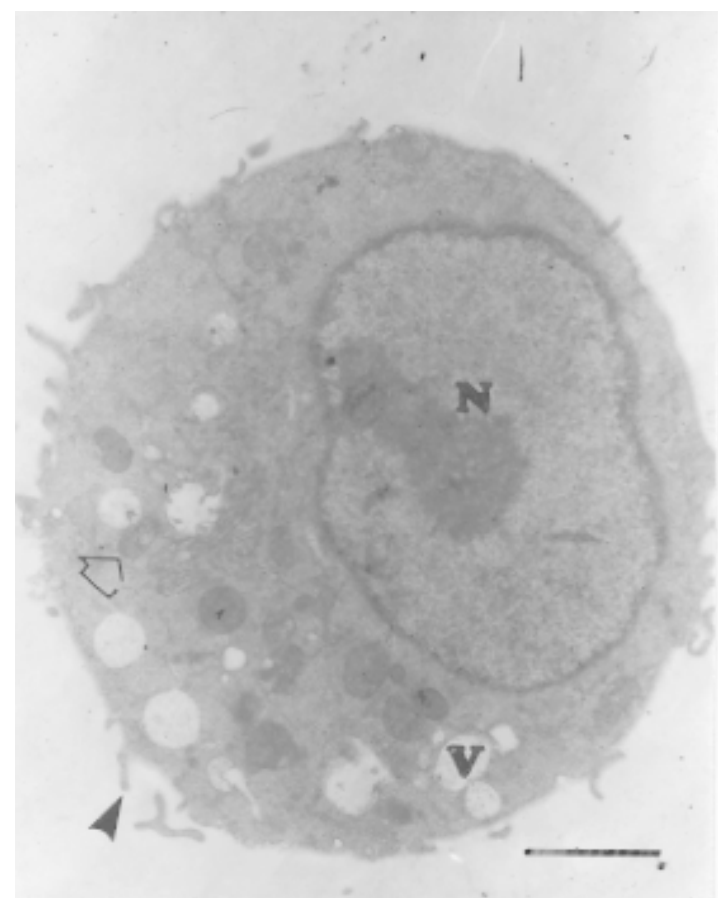

Figura 1. Electromicrografia de una célula FSDC del cultivo control. N: núcleo con nucléolo prominente; V: vacuola; $\Rightarrow$ : mitocondria; $\rightarrow$ :microvellosidad; barra: $3 \mu \mathrm{m}$.

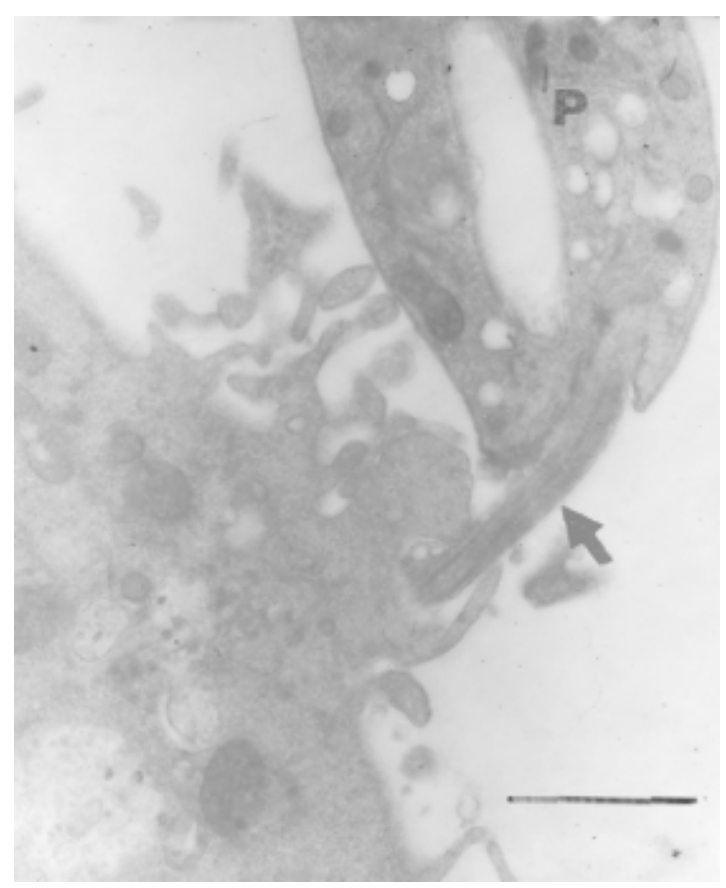

Figura 2. Electromicrografia de un promastigote de $L$. mexicana que se une a la célula a través del flagelo. $P$ : promastigote;

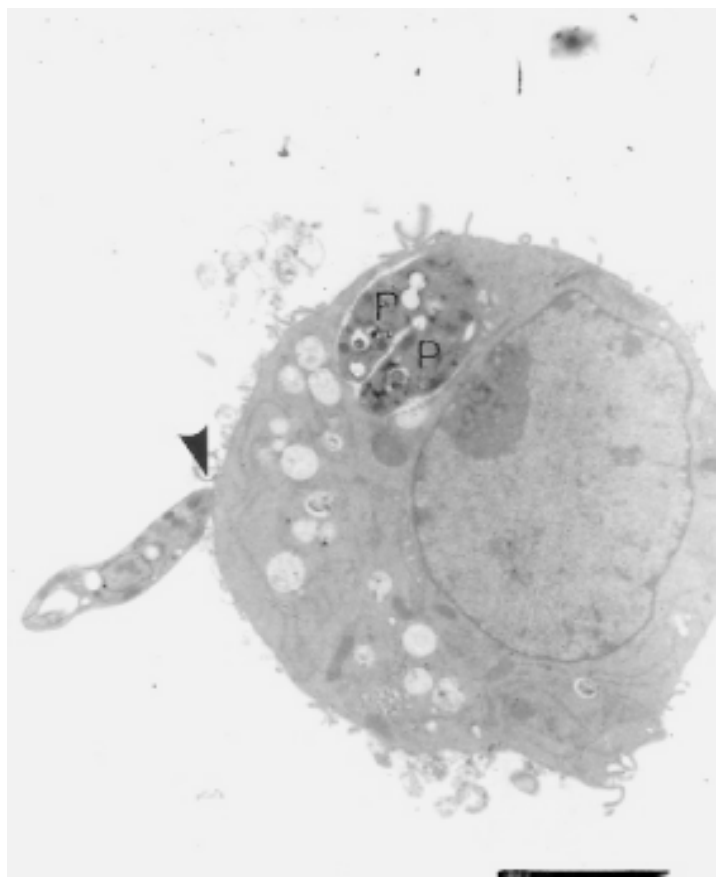

Figura 3. Electromicrografia de un promastigote de $L$. mexicana cuyo polo posterior está en contacto con una FSDC. Se observan dos parásitos $(P)$ dentro de un fagosoma. Barra: $5 \mu \mathrm{m}$.

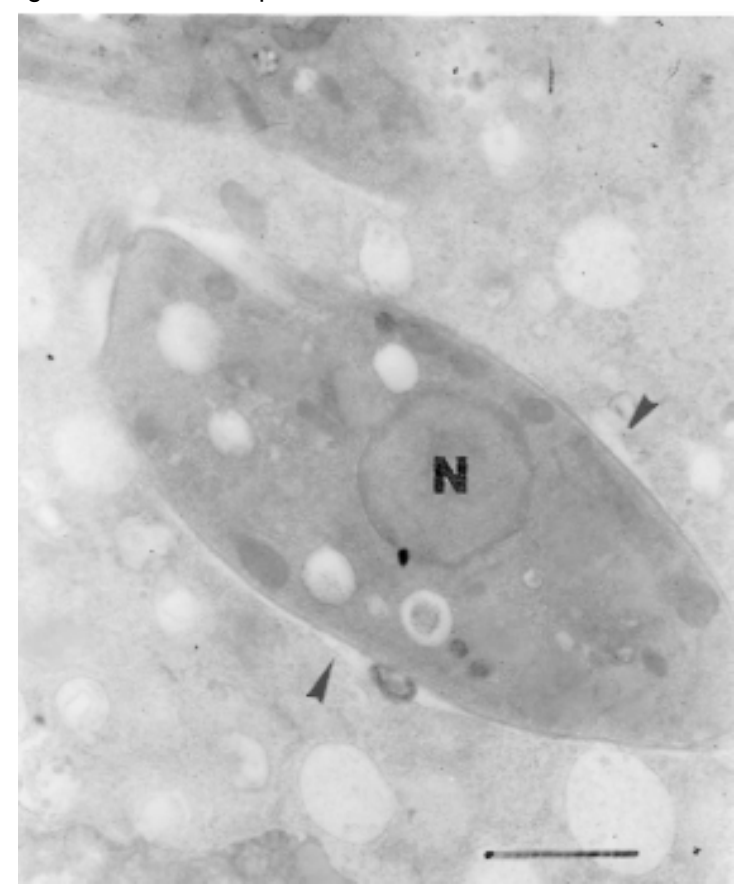

Figura 4. Electromicrografia de un promastigote dentro de fagosoma de la FSDC. Las flechas indican el pequeño espacio entre la membrana del parásito y el fagosoma. $\mathrm{N}$ : núcleo; barra: $1 \mu \mathrm{m}$. 


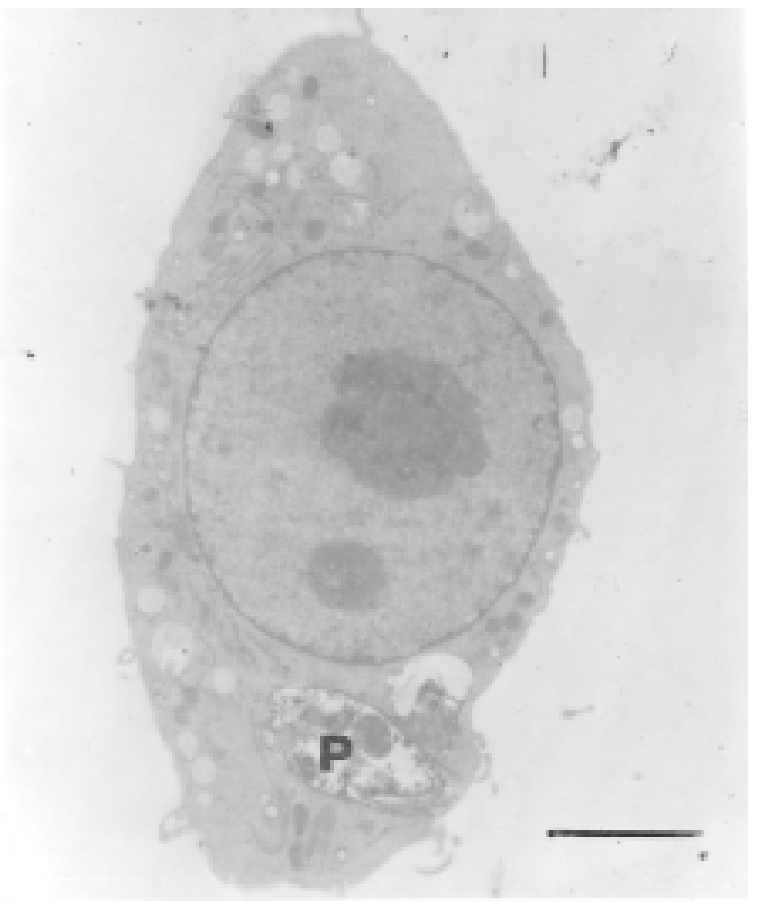

Figura 5. Electromicrografia de una célula FSDC que contiene un promastigote $(p)$ en degradación, como lo demuestra la apariencia vacía del citoplasma por la pérdida de ribosomas. Barra: $5 \mu \mathrm{m}$.

reportados para tipos diferentes de células dendríticas. También presentan similitud con los obtenidos por Moll et al. en cuanto a amastigotes se refiere (4).

La aparente menor captación de parásitos por parte de una célula que se ha venido considerando la iniciadora de la respuesta inmunitaria al transportar el antígeno hasta el ganglio linfático, si bien es un hecho que no necesariamente tiene implicaciones biológicas, sí llama la atención sobre el verdadero papel que esta célula podría estar jugando en el inicio de la respuesta a la enfermedad.

Trabajos recientes demuestran que aunque se pudieron detectar parásitos en el ganglio unas pocas horas después de la infección, éstos estaban en macrófagos. Ninguna célula dendrítica emigrante de la piel tenía parásitos, lo cual indica que no eran las transportadoras. Los parásitos se

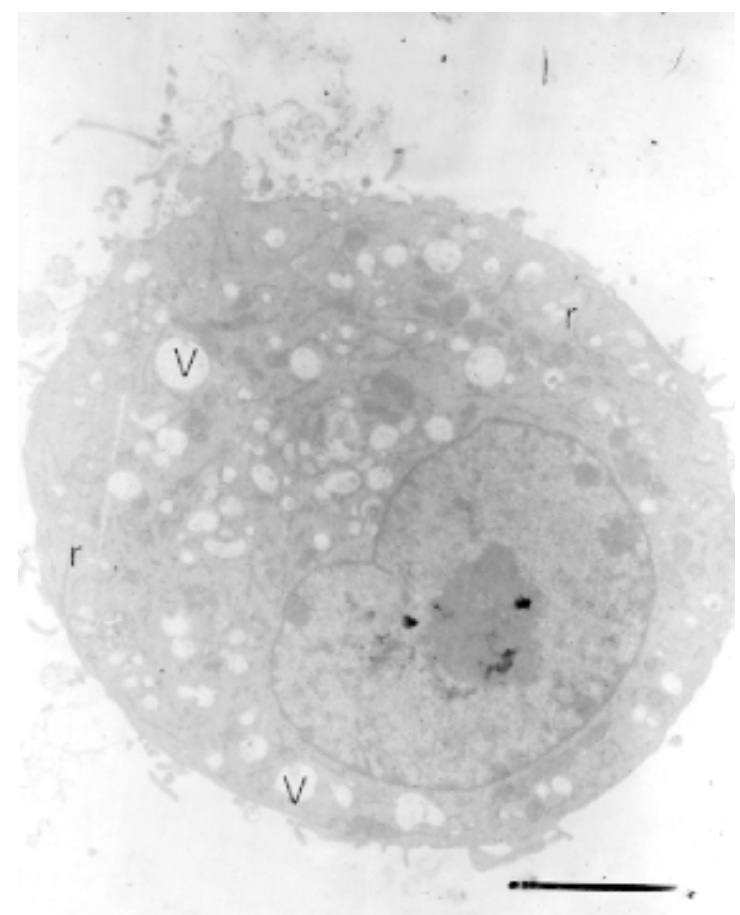

Figura 6. Electromicrografía de una célula FSDC del cultivo infectado. No contiene parásitos en su interior pero evidencia una gran cantidad de vacuolas (v) en su citoplasma. r: retículo endoplasmatico; barra: $5 \mu \mathrm{m}$.

detectaron en células dendríticas en el ganglio sólo tres semanas después de la infección (16).

Otra evidencia muestra que las células dendríticas que transportaban antígeno de Leishmania tres días después de la infección eran de origen dérmico y no epidérmico, concluyendo que las células dendríticas dérmicas y no las células de Langerhans eran las principales presentadoras de antígeno en leishmaniasis (17).

Lemos et al. demostraron que no se requiere de las células de Langerhans para la presentación de antígenos ya que otras células dendríticas pueden desempeñar eficientemente el mismo papel (18). Prina et al. proponen que las células dendríticas en presencia de un bajo número de promastigotes no opsonizados podrían infectarse o no hacerlo por su baja actividad fagocítica, por la competencia con macrófagos residentes o, por el contrario, se infectarían permaneciendo 


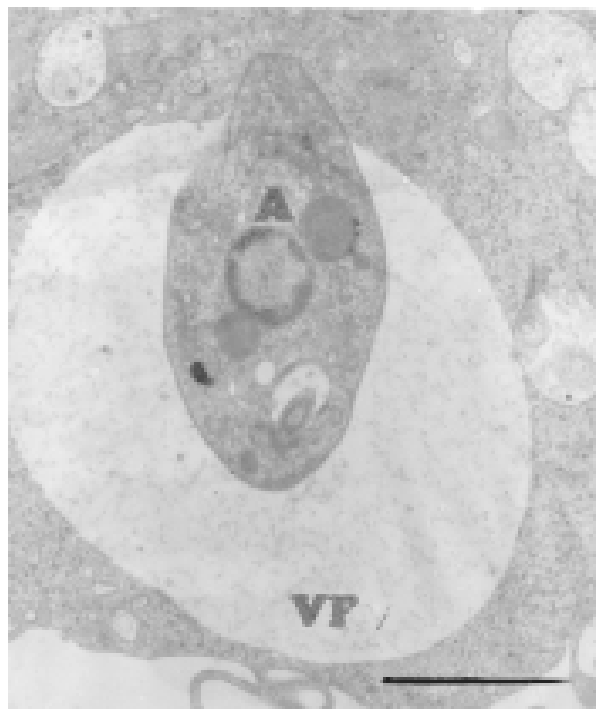

Figura 7. Amastigote de L. mexicana adosado por su polo posterior a un gran fagosoma dentro de la célula FSDC. VP: vacuola parasitófora; A: amastigote; barra: 1,5 $\mu \mathrm{m}$.

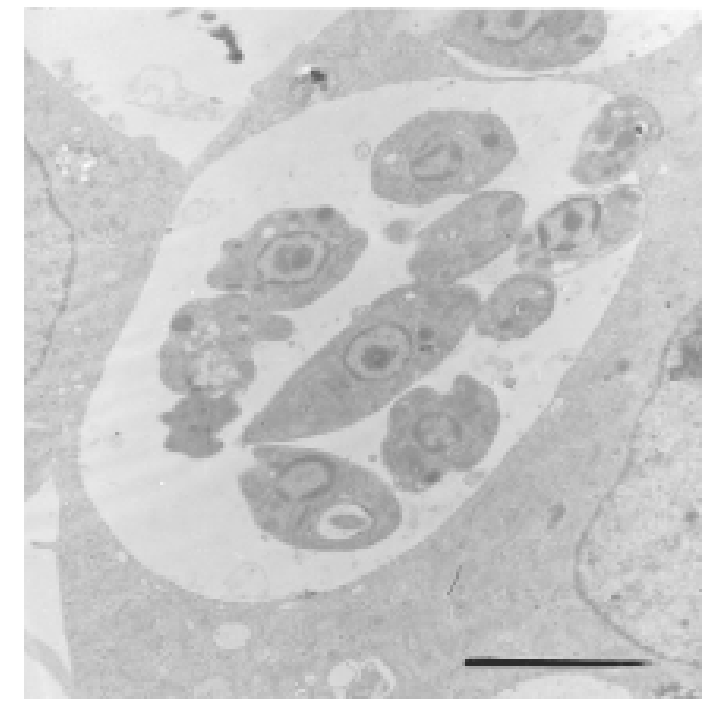

Figura 8. Fagosomas en el citoplasma de una FSDC con gran número de amastigotes de Leishmania adosados y libres. Barra: $5 \mu \mathrm{m}$

inmaduras o en un estadio intermedio que no permitiría la estimulación de los linfocitos T. Por lo tanto, se retardaría el inicio de la respuesta lo que permitiría la amplificación del parásito para, luego, ya en presencia de opsoninas como los anticuerpos, fagocitar los amastigotes, madurar y amplificar la respuesta (6).
Los trabajos que varios grupos están adelantando específicamente en células de Langerhans, permitirán en un futuro aclarar su verdadero papel en el inicio de la respuesta a la leishmaniasis.

Los estudios por videomicroscopía han mostrado que los promastigotes de Leishmania major y Leishmania aethiopica se unen a la célula hospedera de manera predominante por el flagelo $y$, ocasionalmente, por el polo posterior, mientras que Leishmania donovani lo hace por los dos sitios en igual proporción (19); también se ha documentado que Leishmania amazonensis se une al macrófago por los dos polos (20). Nosotros observamos la unión de L. mexicana por los dos polos pero no medimos la frecuencia con la que esto ocurría.

Una vez fagocitado, el promastigote se encuentra en una vacuola parasitófora característicamente muy estrecha, ajustada al parásito a manera de guante, que deja un espacio muy reducido entre el parásito y la membrana de la vacuola.

En los macrófagos, las vacuolas parasitóforas que contienen L. mexicana son grandes $(20,21)$. Se ha identificado un proteofosfoglicano secretado a través del saco flagelar de amastigotes de $L$. mexicana que causa vacuolización de los macrófagos in vitro $(22,23)$. Aparentemente, los amastigotes de L. major no secretan esta molécula y el parásito no induce la formación de grandes vacuolas parasitóforas en macrófagos (23). También se ha encontrado que el agrandamiento de la vacuola parasitófora es menos acentuado en células dendríticas que en macrófagos, lo cual indica que la biogénesis de la vacuola parasitófora es diferente en estas dos células o que su formación es retrasada en células dendríticas (6).

Los amastigotes de L. mexicana se encontraron adheridos a la membrana de la vacuola parasitófora en las FSDC por su polo posterior pero también se encuentran libres dentro de ella, de la misma manera como se ha reportado para las vacuolas parasitóforas formadas en macrófagos (24).

Si bien la aparición de gran cantidad de vacuolas en las células que no fagocitaron puede tener 
causas diversas, una posibilidad es que se deba a un estímulo por parte de las células infectadas, como se ha propuesto (6). Sin embargo, esto tendría que demostrarse por métodos de inmunomicroscopía electrónica para este caso.

La estructura de la vacuola parasitófora y su composición bioquímica ya han sido estudiadas en macrófagos y, más recientemente, en células dendríticas generadas de médula ósea. Se deben hacer estudios encaminados a la caracterización de la vacuola parasitófora formada específicamente en células de Langerhans, en búsqueda de las diferencias que puedan existir con las vacuolas parasitóforas generadas en otros tipos de células dendríticas.

La alta resolución que se logra con la microscopía electrónica (100-200Å), permite aprovechar esta herramienta para el estudio detallado del suceso.

No fue posible inferir sobre la significancia estadística de los resultados entre los dos grupos de células de trabajo, debido a la alta dispersión que presentaron los datos, situación que se refleja en los altos porcentajes de los coeficientes de variación estimados. Sin embargo, se pudo observar que como célula dendrítica, ésta fagocita de manera preferencial un solo parásito. La variación observada podría estar relacionada con el tamaño reducido de las áreas de estudio para microscopía electrónica, de máximo $0,5 \mathrm{~mm}$, y la forma como se distribuye la muestra; aunque la mezcla de células dendríticas y parásitos se hace homogénea, se observan diferencias entre los fragmentos de muestra escogidos.

En conclusión, en cuanto a la estructura fina, se describieron las características de la interacción célula de Langerhans-Leishmania que se relacionaron con cada una de las formas del parásito fagocitado, especialmente en lo que tiene que ver con las diferencias morfológicas de la vacuola parasitófora. Algunas de estas características son similares a las descritas en macrófagos pero no habían sido estudiadas en detalle en células de Langerhans infectadas con Leishmania. Hasta ahora los pocos trabajos que muestran ultraestructuralmente la interacción célula de LangerhansLeishmania, han empleado la microscopía electrónica sólo para documentar la infección.

\section{Agradecimientos}

A María Carlina Castillo por su asesoría en el análisis estadístico.

\section{Conflicto de intereses}

Los autores manifiestan que no existe ningún conflicto de intereses.

\section{Financiación}

Instituto Colombiano para el Desarrollo de la Ciencia y la Tecnología - Colciencias (proyecto 2104-04-10240), Banco Interamericano de Desarrollo, Instituto Nacional de Salud y FONACIT, Proyecto S1-2001000847.

\section{Referencias}

1. Brandonisio O, Spinelli R, Pepe M. Dendritic cells in Leishmania infection. Microbes Infect 2004;6:1402-9.

2. Sarmiento L, Peña S. La célula de Langerhans. Biomédica 2003;22:462-5.

3. Zuluaga M, Robledo SM. Las células de Langerhans en la inmunidad a leishmaniasis. Biomédica 2004;24:30217.

4. Blank C, Fuchs H, Rappersberger K, Rollinghoff M, Moll H. Parasitism of epidermal Langerhans cells in experimental cutaneous leishmaniasis with Leishmania major. J Infect Dis 1993;167:418-25.

5. von Stebut E, Belkaid Y, Jakob T, Sacks DL, Udey MC. Uptake of Leishmania major amastigotes results in activation and interleukin 12 release from murine skin derived dendritic cells: Implications for the initiation of anti Leishmania immunity. J Exp Med 1998;188:154752.

6. Prina E, Abdi SZ, Lebastard M, Perret E, Winter N, Antoine JC. Dendritic cells as host cells for the promastigote and amastigote stages of Leishmania amazonensis: the role of opsonins in parasite uptake and dendritic cell maturation. J Cell Sci 2004;117:31525.

7. Qi H, Popov V, Soong L. Leishmania amazonensis dendritic cell interactions in vitro and the priming of parasite specific CD4(+) T cells in vivo. J Immunol 2001;167:4534-42.

8. Marovich MA, Mc Dowell MA, Thomas EK, Nutman TB. IL 12 p70 production by Leishmania major harboring human dendritic cells is a CD40/CD40 ligand dependent process. J Immunol 2000;164:5858-65.

9. Konecny $\mathbf{P}$, Stagg AJ, Jebbari H, English N, Davidson RN, Knight SC. Murine dendritic cells internalize Leishmania major promastigotes, produce IL $12 \mathrm{p} 40$ and stimulate primary $\mathrm{T}$ cell proliferation in vitro. Eur J Immunol 1999;29:1803-11. 
10. Saraiva E, Pimenta F, Pereira M, de Souza W. Isolation and purification of amastigotes of Leishmania mexicana amazonensis by a gradient of metrizamide. J Parasitol 1983;69:627-9.

11. Girolomoni G, Lutz MB, Pastore S, Assmann CU, Cavani A, Ricciardi-Castagnoli P. Establishment of a cell line with features of early dendritic cell precursors from fetal mouse skin. Eur J Immunol 1995;25: 2163-9.

12. Chaker MB, Tharp MD, Bergstresser PR. Rodent epidermal Langerhans cells demonstrate greater histochemical specificity for ADP than for ATP and AMP. J Invest Dermatol 1984;82:496-500.

13. Citterio S, Foti M, Granucci F, Matyszak M, Girolomoni G, Ricciardi-Castagnoli P. Generation of mouse dendritic cell lines. En: Robinson S, Stagg A, editors. Dendritic cell protocols. New Jersey: Humana Press; 2001. p.219-30.

14. García del Moral R. Laboratorio de Anatomía Patológica. Madrid: McGraw-Hill Interamericana; 1993.

15. Gilchrist K, Robledo $\mathbf{S}$. Las células dendríticas y su interacción con parásitos de Leishmania. Acta Med Colomb 2003;28:117-26.

16. Baldwin T, Henri S, Curtis J, O'Keeffe M, Vremec $\mathrm{D}$, Shortman $\mathrm{K}$ et al. Dendritic cell populations in Leishmania major infected skin and draining lymph nodes. Infec Immun 2004;72:1991-2001.

17. Ritter U, Meissner A, Scheidig C, Korner H. CD8 alpha- and Langerin negative dendritic cells, but not Langerhans cells, act as principal antigen-presenting cells in leishmaniasis. Eur J Immunol 2004;34:1542-50.
18. Lemos MP, Fan L, Lo D, Laufer TM. CD8á+ and CD11b+ dendritic cell restricted MHC class II controls Th1 CD4+T cell immunity. J Immunol 2003; 171:507784.

19. Rittig MG, Schroppel K, Seack KH, Sander U, N'Diaye EN, Maridonneau-Parini I et al. Coiling phagocytosis of trypanosomatids and fungal cells. Infec Immun 1998; 66:4331-9.

20. Courret N, Frehel C, Gouhier N, Pouchelet M, Prina $\mathbf{E}$, Roux $\mathbf{P}$ et al. Biogenesis of Leishmania vacuoles following phagocytosis of the metacyclic promastigote or amastigote stages of the parasite. J Cell Sci 2002;115:2303-16.

21. Antoine JC, Prina E, Lang T, Courret N. The biogenesis and properties of the parasitophorous vacuoles that harbour Leishmania in murine macrophages. Trends Microbiol 1998;6:392-401.

22. Ilg T, Srierhof YD, McConville MJ, Overath P. Purification, partial characterization and immunolocalization of a proteophosphoglycan secreted by Leishmania mexicana amastigotes. Eur J Cell Biol 1995; 66:205-15.

23. Peters C, Stierhof YD, IIg T. Proteophosphoglycan secreted by Leishmania mexicana amastigotes causes vacuole formation in macrophages. Infect Immun 1997;65:783-6.

24. Benchimol M, de Souza W. Leishmania mexicana amazonensis: attachment to the membrane of the phagocytic vacuole of macrophages in vivo. Z Parasitenkd 1981;66:25-9. 